\title{
Nuestras Investigaciones Sobre la Fisiología de la Eyección Láctea en la Mujer
}

\author{
Dr.: Edgard Cobo*
}

“A LO HECHO .. . PECHO”

Del refranero popular.

Afiche para la promoción de la lactancia

Dra. Ada Ovies. Directora. Maternidad de Güines. Provincia de la Habana. Cuba.

El propósito de este artículo es rendir un doble homenaje: el primero a la conmemoración de los primeros 40 años de publicación ininterrumpida de la Revista Colombiana de Obstetricia y Ginecología y el segundo a la Universidad del Valle, en cuya Facultad de Medicina, un grupo de pioneros supo crear las bases de un modelo educativo que estimuló la práctica de la investigación científica en un medio ambiente, por diversas razones, adverso. Y la forma en que le resulta más justo y más grato hacerlo a quien, como el autor de estas líneas, tuvo siempre el privilegio de disfrutar el fresco ambiente de ambas instituciones, es la de ofrecerles un resumen del esfuerzo creador realizado en una de las tantas líneas de trabajo, que se desarrollaron en el ya desaparecido Laboratorio de Fisiología de la Reproducción, del Departamento de Obstetricia y Ginecología de la Facultad y que hoy sigue su lucha como una nueva empresa: La Fundación para la Investigación en Reproducción y Medicina Perinatal (INVEST). La línea de trabajo a la cual nos referi-

\footnotetext{
* Profesor Titular y Emérito de Obstetricia y Ginecología de la Facultad de Salud. Universidad del Valle.

* Expresidente de la Federación Colombiana de Sociedades de Obstetricia y Ginecología.
}

mos es la fisiología de la eyección láctea en la mujer.

La lactancia es un proceso que extiende sus raices hasta la vida embrionaria cuando se inicia la formación de la glándula mamaria y que puede llegar a reactivarse hasta después de los 70 años de edad. Ha sido dividida con propósitos didácticos en cinco fases fundamentales: mamogénesis, o formación y crecimiento de la glándula mamaria; lactogénesis, o iniciación de la secreción láctea; evección láctea, o expulsión de la leche al exterior por contracción de las células mioepiteliales que rodean a los alveolos y conductos mamarios; galactopoiesis, o prolongación de la secreción láctea y finalmente, la ingestión láctea, que incluye aquellos mecanismos aportados por el recién nacido y el lactante para la producción de su alimento básico: la leche materna.

Se ha dicho que la sobrevivencia de la especie humana, en condiciones naturales depende de 2 actos bio-reproductivos voluntarios: el coito y la lactancia. Y en efecto, si se analiza la mortalidad infantil en el mundo no desarrollado, se encuentran todavía muchos lugares que, como testigos asombrados, sufren los efectos de esta afirmación milenaria.

Debe destacarse que la eyección láctea aparece como la pieza maestra del sistema, ya que a través de la succión del pezón, no solo se estimula la eyección láctea propiamente dicha, sino todas las demás fases fundamentales de la lactancia. Existen evidencias que demuestran como la succión repetida del pezón produce lactancia natural en situaciones 
desusadas, como las informadas por Michael Newton, brillante investigador de la Universidad de Mississippi, quien narra, con un realismo GarcíaMarquiano, como abuelas de 60 y más años han logrado amamantar a sus nietos; como un hombre de 70 años logró amamantar a su propio hijo después de la muerte de su esposa, y como un marinero inglés, quien naufragó con un lactante, aseguró su sobrevivencia coloćandolo a succionar sus pezones. En la actualidad un grupo de trabajo de Buenos Aires, llamado Nu-Ñú, tiene un exitoso programa de inducción de la lactancia en madres adoptivas, por medio de la succión del pezón.

Nuestro interés en este tema nació en Montevideo, cuando entre 1959 y 1961 , el autor fuera becario en el Servicio de Fisiología Obstétrica, y participara en los trabajos iniciales de Yamandú SicaBlanco, en la actualidad Profesor Titular de Obstetricia y Ginecología, y en esa época colaborador distinguidísimo de Hermógenes Alvarez y Roberto Caldeyro Barcia, suficientemente conocidos en nuestro medio. En ese entonces, él desarrolló un método para medir la presión intraductal mamaria en la mujer lactante mediante el cual, diseñando y enseñando, produjo con algunos de sus alumrios entre quienes me sigo contando, sus primeros y valiosos trabajos experimentales. En 1962, ya en Cali, quisimos estudiar la función hipotálamo-neurohipofisiaria en madres con toxemia del embarazo, pero encontramos que se desconocían muchos aspectos básicos de dicha función en las embarazadas normales. Decidimos entonces, comenzar con el estudio de las características de la liberación de oxitocina y de hormona antidiurética en las mujeres normales durante el embarazo, el parto y la lactancia. Pero cediendo ante la fascinación que despertaron en nosotros los primeros hallazgos, fuimos abandonando la idea inicial de la toxemia del embarazo y dedicamos todo nuestro esfuerzo, en esa época afortunada del tiempo completo y la dedicación exclusiva, al estudio de las áreas cuyos resultados resumiremos adelante. Hoy, la crisis que vive la Universidad de todo el continente y a la cual no solo no escapamos, sino que vivimos con más profundidad que otros países por razones cuyo análisis escapa al marco de este artículo, esta línea continúa una débil trayectoria, a cuya revitalización estamos aportando un decidido entusiamo. Vamos pues, a intentar ese resumen de las áreas estudiadas, en un orden aproximadamente cronológico.

\section{La Liberación Diferencial de Oxitocina y Hormona Antidiurética}

Existía una marcada controversia sobre la forma como se liberan estas hormonas frente a estímulos capaces de activar el sistema hipotálamo-hipofisiario, tales como la succión del lactante, o la hipertonicidad del plasma sanguineo, por ejemplo. Algunos autores habían descrito en especies inferiores y aún en la mujer, la liberación simultánea de oxitocina y hormona antidiurética (ADH) frente al estímulo de la succión del pezón. Otros sugerian la liberación específica de oxitocina en situaciones como el parto y posiblemente la lactancia.

En 37 mujeres lactantes que aceptaron voluntariamente ingresar al proyecto nosotros estudiamos la liberación de oxitocina midiendo el incremento en la presión intramamaria, mediante el método de Sica. La actividad eyectoláctea se indujo realizando succión del lactante en la mama no cateterizada. Expresamos dicha actividad eyectoláctea en $\mathrm{mm}^{2}$ por minuto. También estudiamos la dilatación instrumental de los galactóforos, como otro estímulo liberador de oxitocina. La liberación de ADH se estudió midiendo la osmolaridad y la concentración de creatinina endógena en la sangre y la orina, en condiciones de diuresis acuosa inducida.

\section{FIGURA 1}
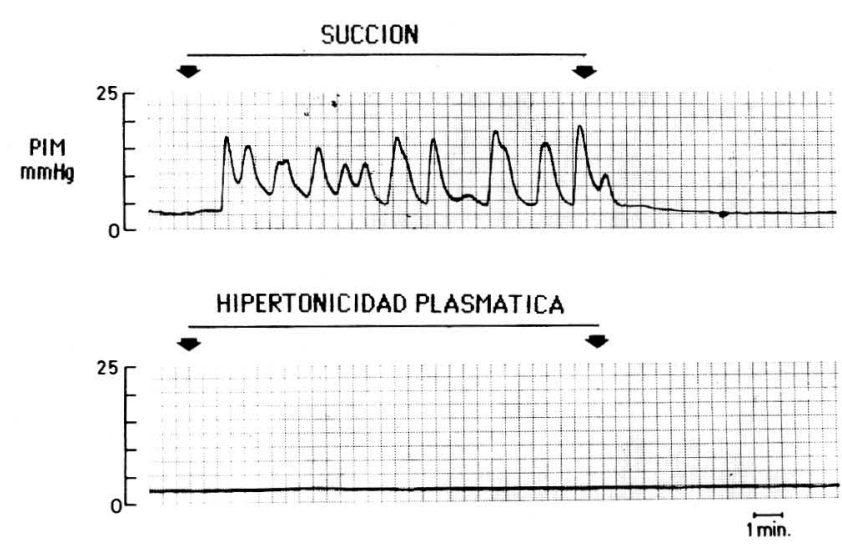

Registro de presión intraductal mamaria (PIM) en una mujer lactante. El trazado superior muestra como la succión del lactante induce actividad eyectoláctea caracterizada por elevaciones continuas de la PIM, en forma de contracciones incoordinadas y desiguales. En el trazado inferior se muestra como la hipertonicidad del plasma, inducida con $\mathrm{C} 1 \mathrm{Na}$, no produce actividad eyectoláctea. 
Calculamos la depuración de agua libre, de creatinina y de solutos, los cuales se expresaron en milimetros por minuto ( $\mathrm{ml} / \mathrm{min}$ ).

Nuestros resultados demostraron por primera vez, que tanto la succión del lactante (Figura 1) como la dilatación de un galactóforo mamario, inducían la liberación de oxitocina, pero no la liberación simultánea de $\mathrm{ADH}$ (Figura 2). Y al contrario, cuando se aumentaba la osmolaridad del plasma, (Figura 1) o se administraban pequeñas dosis de nicotina i.v., se obtenía una clara liberación de $\mathrm{ADH}$,

FIGURA 2

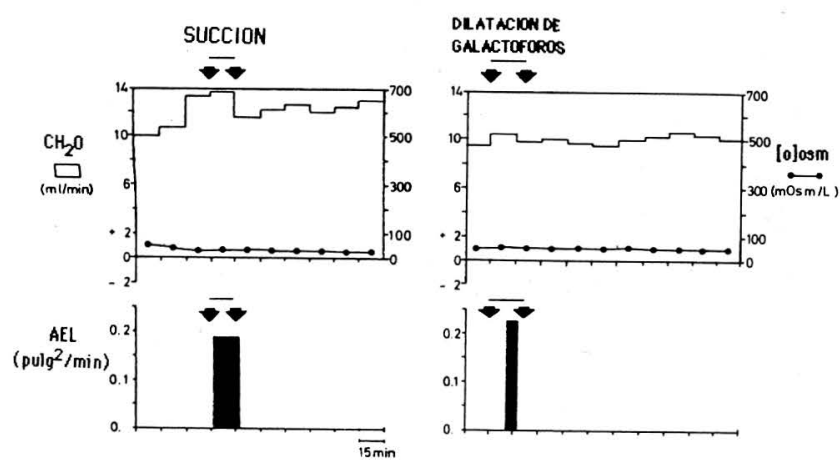

Medida de las actividades antidiurética y eyectoláctea con estímulos inductores de liberación de oxitocina. En las ordenadas: $\mathrm{CH}_{2} \mathrm{O}=$ depuración de agua libre: [0 ] osm =osmolaridad urinaria y $\mathrm{AEL}=$ actividad eyectoláctea. Obsérvese como no hay ninguna modificación en la actividad antidiurética (cuadros superiores), pero en cambio es evidente una clara actividad eyectolác tea (cuadros inferiores) con los 2 estímulos usados: succión y dilatación de galactóforos.

pero no de oxitocina (Figura 3). Era bastante evidente entonces, que en la especie humana, a diferencia de otras especies, la liberación de ambas hormonas se producía como respuesta a estímulos específicos, sugiriendo posibilidades entre las cuales destacamos: a) que fueran distintos los trayectos de las vías neurales aferentes, que a través de la médula espinal, llegan al sistema hipotálamo-neurohipofisiario, o b), que los mecanismos neurohipofisiarios de modulación de la respuesta hormonal, fueran diferentes para ambas hormonas. Planteamos también que estas diferencias con especies animales inferiores bien podrían ser un resultado del proceso evolu- tivo, que en esta situación se expresa adquiriendo la fina capacidad de discriminar estímulos específicos.

\section{FIGURA 3}

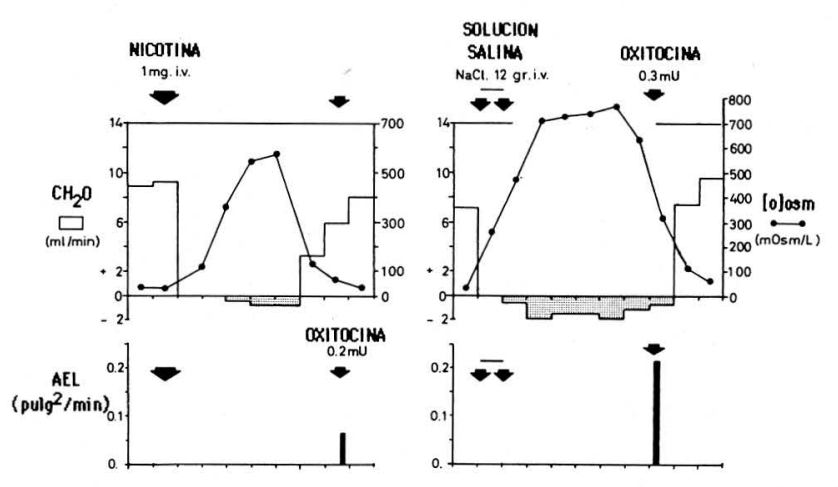

Medida de las actividades antidiurética y eyectoláctea con estímulos inductores de la liberación de $A D H$. Igual forma de representación que en la figura anterior. Se aprecia una marcada actividad antidiurética tanto con la administración de $1 \mathrm{mg}$. i.v. de nicotina (izquierda), como con la de $12 \mathrm{gr}$. i.v. de $\mathrm{C} 1 \mathrm{Na}$ en infusión continua de $15 \mathrm{~min}$. Obsérvese cómo estos estímulos no inducen actividad eyectoláctea, a pesar de que la paciente tiene una gran sensibilidad a la oxitocina, que produce respuestas con dosis de 0.2 y $0.3 \mathrm{mU}$ (200 y 300 microunidades, respectivamente).

Estos resultados han sido apoyados posteriormente en trabajos de fisiología básica. En la mujer, también ha sido confirmada la liberación diferencial, en trabajos publicados 15 años después de los nuestros, por el grupo de Richard Weitzman, Rosemary Leake y colaboradores, de la Universidad de California en los Angeles, midiendo oxitocina y $\mathrm{ADH}$ por radioinmunoanálisis.

\section{El Patrón de Secreción de Oxitocina y ADH}

Varias preguntas aparecían lógicas después de encontrarnos con semejante evidencia de liberación diferencial, como: ¿Hay diferencias también en los patrones o formas de liberación de ambas hormonas?, o ¿La inhibición experimental del sistema sigue también en el modelo diferencial?. Vamos a detenernos por ahora en la primera pregunta. Un poco más adelante expondremos la respuesta a la segunda de ellas. Después plantearemos muchas otras y resumiremos nuestras respuestas. 
Utilizando la misma metodología descrita atrás, decidimos reproducir los efectos eyectolácteos y antidiuréticos resultantes de los 4 estímulos realizados: succión del lactante, dilatación de galactóforos y administración de soluciones salinas hipertónicas y de nicotina. Para ello administramos oxitocina y arguinina-vasopresina sintéticas por vía endovenosa, tanto en infusiones continuas, como en dosis únicas, en 35 lactantes voluntarias.

Nuestros resultados demostraron la existencia de un patrón de liberación que también era diferente para ambas hormonas. En efecto, la administración de oxitocina sólo podía reproducir el patrón de liberación inducido por la succión cuando era administrada en dosis únicas e intermitentes y no cuando se administraba en otras formas (Figura 4). En cambio, la reproducción de los efectos antidiuréticos producidos por la hipertonicidad del plasma solo se obtuvo mediante la administración de infu-

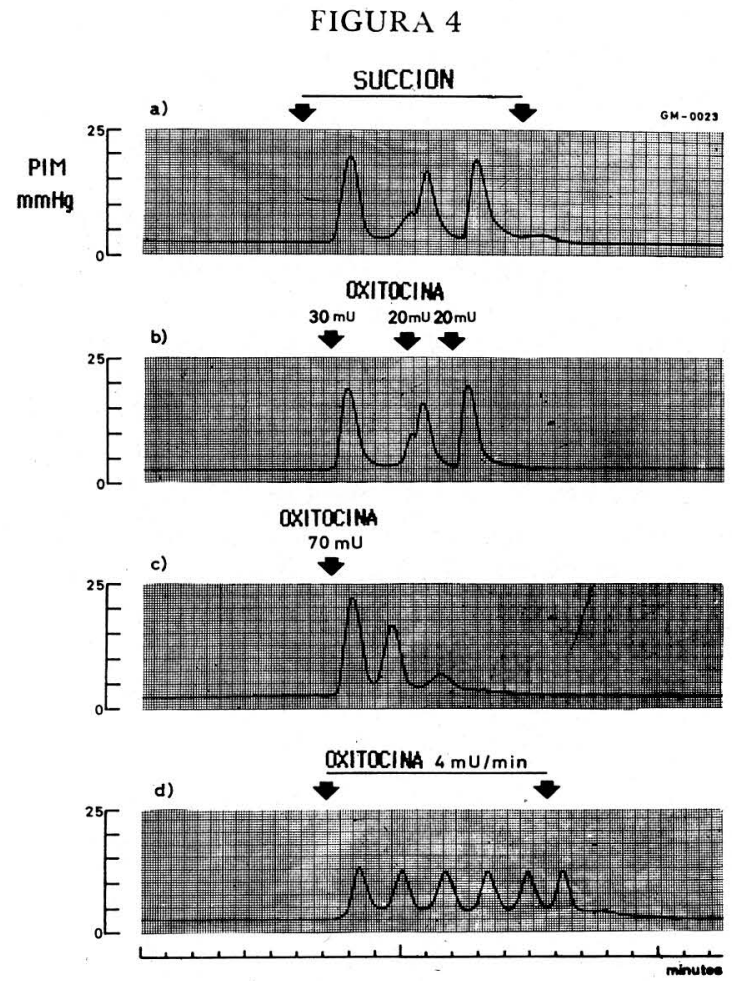

Reproducción del patrón de liberación de oxitocina con la succión. A. Respuesta mamaria normal a la succión del lactante; B. Reproducción casi exacta de la respuesta normal administrando $70 \mathrm{mU}$ de oxitocina, fraccionadas en forma intermitente, en dosis de 30, 20 y $20 \mathrm{mU}$; C. La administración única de $70 \mathrm{mU}$, no reproduce el efecto, como tampoco lo hace en el trazado; D. una infusión continua de $4 \mathrm{mU} / \mathrm{min}$.

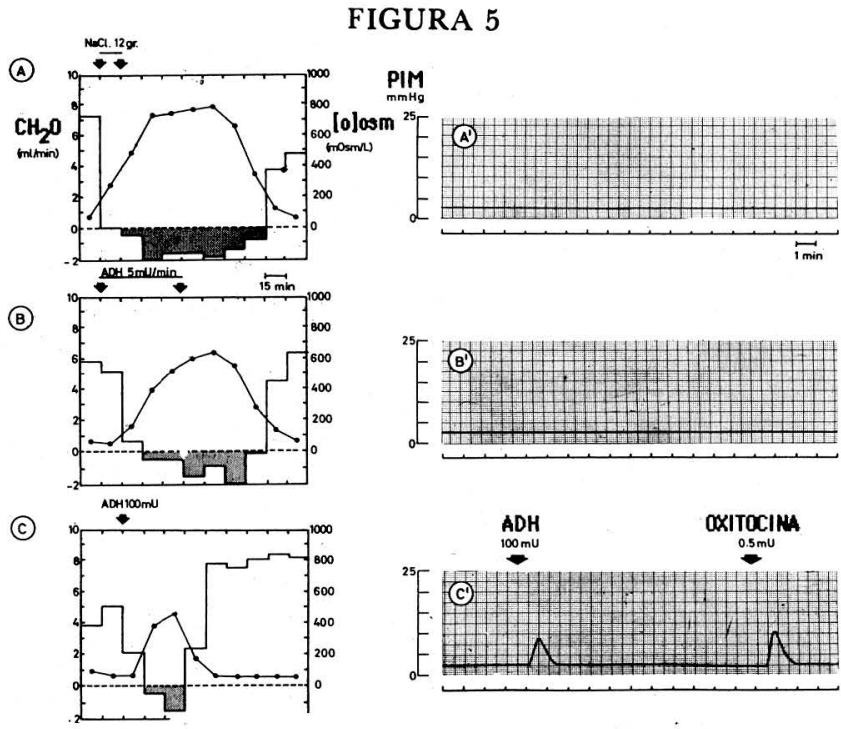

Reproducción del patrón de liberación de hormona antidiurética con hipertonicidad del plasma. A, respuesta antidiurética normal; $\mathrm{B}$, reproducción del efecto normal, con una infusión continua de $\mathrm{ADH}$ a $5 \mathrm{mU} / \mathrm{min}$; C, efecto pobre y actividad eyectoláctea (debida a la actividad oxitócica 1:80 propia de la molécula de $\mathrm{ADH}$ ) simultánea.

\section{FIGURA 6}

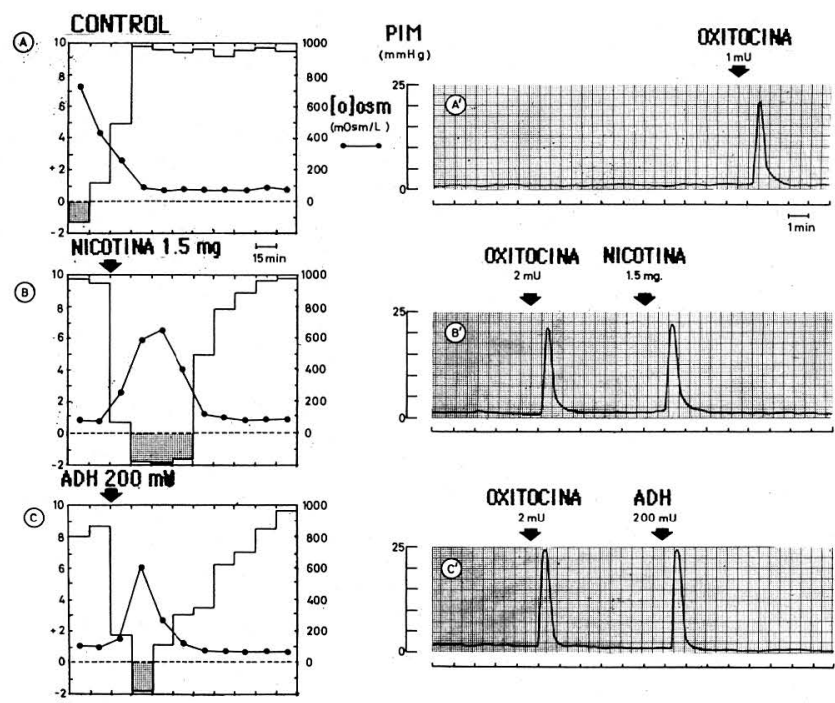

Reproducción del patrón de liberación de ADH con nicotina. $\mathrm{A}$, Control en diuresis acuosa; $\mathrm{B}$, efecto antidiurético inducido farmacológicamente con $1,5 \mathrm{mg}$. de nicotina, que induce además actividad eyectoláctea; $\mathrm{C}$, reproducción de ambos efectos con $200 \mathrm{mU}$ de $\mathrm{ADH}$. 
siones endovenosas continuas de arguinina-vasopresina (Figura 5) del orden de 1 a 5 miliunidades por minuto $(\mathrm{mU} / \mathrm{min})$. La reproducción del efecto de la nicotina se logró con dosis únicas del orden de 40 a 200 miliunidades de la misma hormona (Figura 6).

Sugerimos entonces que la succión inducía un patrón pulsátil o intermitente de liberación central la oxitocina, cuando, en contraste, la hipertonicidad del plasma inducía un sistema de liberación continua de hormona antidiurética y,de liberación súbita y corta de esta misma hormona cuando se administraba nicotina.

Estos hallazgos reforzaron nuestra hipótesis previa de especificidad de estímulos, en el sistema hipotálamo-neurohipofisiario de la mujer lactante.

\section{La Magnitud de Liberación de Oxitocina Durante la Succión del Lactante}

En 1965, Juan Coch y sus colaboradores, habían realizado en Montevideo, un dispendioso experimento que buscaba medir la cantidad de oxitocina liberada por la succión. Utilizando un método de bioensayo con glándula mamaria de coneja "in vivo", analizaron muestras de sangre extraída de la vena yugular de mujeres lactantes. Sus resultados demostraron la presencia de una sustancia con las mismas características cromatográficas, electroforéticas y farmacológicas de la oxitocina, en concentraciones que fluctuaban entre 12 y 25 microunidades por mililitro $(\mu \mathrm{U} / \mathrm{ml})$. Estas concentraciones podrían calcularse como equivalentes a las producidas por infusiones continuas de oxitocina sintética en dosis que fluctuarán entre 4 y $8 \mathrm{mU} / \mathrm{min}$, según trabajos realizados por Venus-González-Panizza y Yamandú Sica-Blanco y colaboradores del mismo Servicio de Fisiología Obstétrica. O sea, que para una succión de 10 minutos, sería necesaria la liberación neurohipofisiaria de 40 a $80 \mathrm{mU}$ de la hormona.

Nosotros aplicamos en 24 lactantes voluntarias el diseño descrito atrás, pero administrando solo dosis únicas e intermitentes que permitieran una reproducción farmacológica del efecto fisiológico de la succión del lactante realizada durante $10 \mathrm{mi}$ nutos. Encontramos que la cantidad de oxitocina liberada fluctuaba entre 40 y 180 miliunidades en 10 minutos, siendo el promedio de $101.9 \pm 8.4$ (SEM)
FIGURA 7

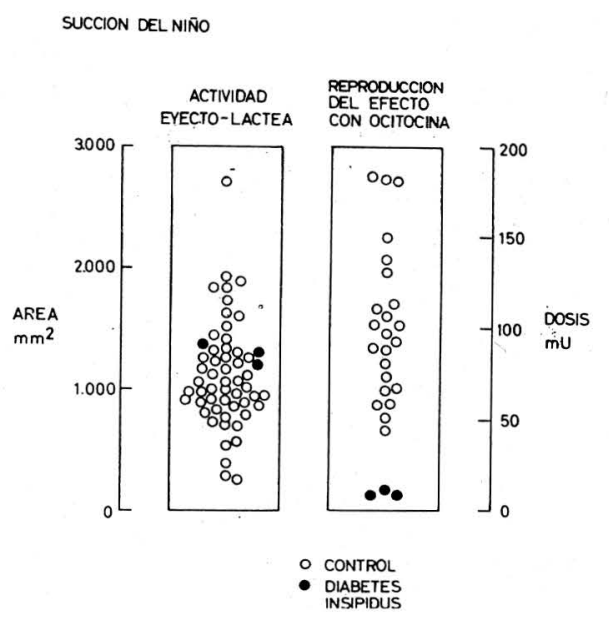

Valores normales de actividad eyectoláctea inducida por succión (izquierda) y cantidad de oxitocina estimada por dosis que aparean dichos valores normales. La actividad eyectoláctea se expresa como área integrada de las contracciones registradas $\left(\mathrm{mm}^{2}\right)$ en 55 casos de succión,y se aparea bien con dosis entre 40 y $180 \mathrm{mU}$ de oxitocina. Obsérvense las bajas dosis de oxitocina $(10 \mathrm{a} 12 \mathrm{mU})$ necesarias para reproducir el efecto de la succión en un caso de diabetes insípida completa (puntos negros).

miliunidades (Figura 7). Estos resultados se asemejan a los publicados por Sica-Blanco, anotados en el párrafo anterior y difieren de los publicados por Néstor Sala, de Buenos Aires, Argentina, quien encontró cantidades menores utilizando una metodología un poco diferente a la utilizada por nosotros. Lamentablemente, su desafortunada y prematura desaparición física, dejó en ese punto una gratísima polémica científica, llevada con una altura digna de su amistad y de su estirpe, que no nos dio tiempo para explorar la posibilidad de que la cantidad de oxitocina necesaria para la respuesta eyectoláctea fuera disminuyendo en la medida en que avanzaba el tiempo de la lactancia, lo cual pudiera habernos dado alguna claridad sobre esa diferencia.

Ya nosotros habíamos encontrado que pueden existir variaciones en la sensibilidad del órgano efector, o sea en el mioepitelio mamario. En efecto, en un paciente con diabetes insípida completa, o sea, con una liberación muy disminuída de hormonas neurohipofisiarias, logramos reproducir el efecto de la succión del lactante con solo $11.5 \mathrm{mU}$ de oxitocina, (Figura 8), la más baja cantidad utiliza- 
da en centenares de casos. Este hallazgo establece una relación entre la liberación central y la sensibilidad del sistema de recepción periférica y plantea un mecanismo de compensación que haría que frente a cantidades limitadas de producción hormonal neurohipofisiaria, el mioepitelio mamario aumentara su capacidad de respuesta a esa hormona.

FIGURA 8

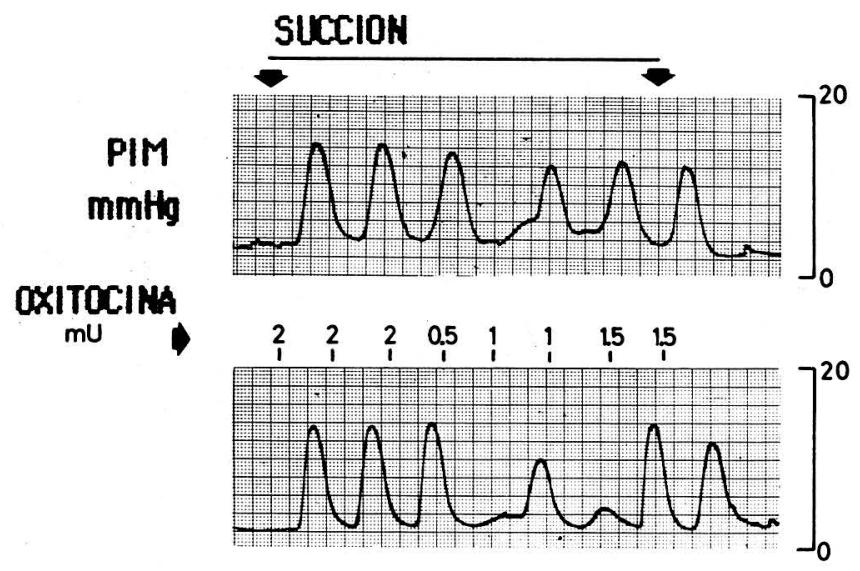

Reproducción experimental de la respuesta normal a la succión (arriba), con dosis intermitentes bajas de oxitocina exógena (abajo), en un caso de diabetes insípida completa.

Volviendo a la magnitud de la respuesta, digamos que resultados publicados por el grupo de la Universidad de California en los Angeles, informan una concentración creciente de oxitocina en la sangre periférica que llega a un pico de $6.4 \pm 1.5$ $\mathrm{mU} / \mathrm{ml}$, a los 6 minutos de iniciada la succión y que varía poco hasta los 15 minutos. Si se tiene en cuenta que las concentraciones de oxitocina en la sangre periférica son entre 5 y 10 veces menores que en la yugular, hay una ajustada correlación entre la magnitud de la liberación de oxitocina encontrada por este grupo de los Angeles y la encontrada por demas investigadores mencionados, utilizando diseños y métodos muy diferentes, en mujeres lactantes.

\section{La Hormona Eyecto-Láctea}

Aunque no hacía parte de los proyectos directamente relacionados con la lactancia humana, ocurrió en 1968 un resultado notable e inesperado en otra línea de trabajo que veníamos desarrollando simultánemanete, orientada hacia el estudio de la función hipotálamo-neurohipofisiaria duran te el parto, y que se relaciona con el tema que veníamos tratando.

Sucedió que, habiéndose establecido que el mioepitelio mamario era un órgano efector, u órgano blanco, más sensible y específico que el útero a la administración de oxitocina, decidimos registrar simultáneamente la presión intramamaria y la intraamniótica durante el trabajo de parto, después de haber explorado adecuadamente la alta sensibilidad mamaria a dicha hormona durante la fase de preparto, en 13 mujeres que aceptaron el procedimiento.

\section{FIGURA 9}
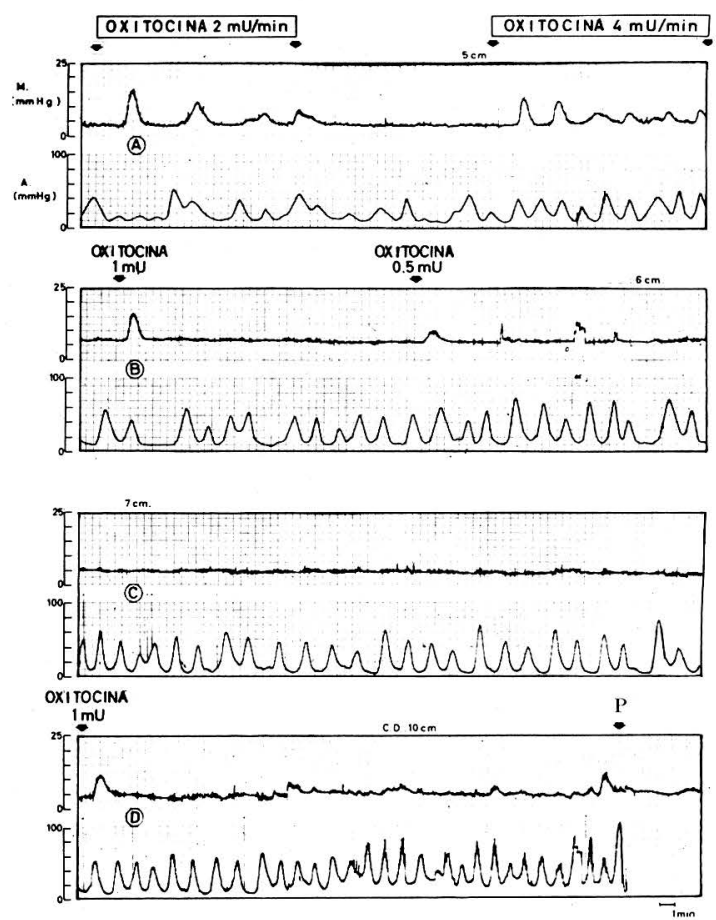

Registro simultáneo de actividades eyectolácteas (M) uterina (A) durante un parto espontáneo y normal. A, la administración de 2 y $4 \mathrm{mU} / \mathrm{min}$. de oxitocina induce una clara actividad eyectoláctea, cuando la diltación cervical (DC) es de 5 $\mathrm{cm}$. $\mathrm{B}$, la administración en dosis únicas de 0.5 y $1 \mathrm{mU}$ produce claras respuestas mamarias; la DC es de $6 \mathrm{~cm}$, C, a pesar de una alta actividad uterina cuando ya hay $7 \mathrm{~cm}$. de DC, no se observa actividad eyectoláctea espontánea (que induciría la oxitocina endógena si estuviera presente). Como tampoco se observa en el segmento $D$, correspondiente al final del primer período del parto, al período del parto y al parto mismo (P). 
Encontramos que durante el parto no ocurrían contracciones del mioepitelio mamario, cuando al mismo tiempo el útero presentaba contracciones correspondientes a la fase activa y al período expulsivo (Figura 9). Concluímos entonces, y lo comunicamos por primera vez a la literatura médica, que nuestros resultados sugerían de manera casi concluyente, que la oxitocina no era una hormona necesaria, ni para la iniciación, ni para el desarrollo del trabajo de parto humano. Posteriormente, ampliamos estos resultados al registrar 3 partos espontáneos en nuestra paciente con diabetes insípida completa y finalmente, algunos meses después, administramos a 5 mujeres voluntarias, alcohol etílico disuelto en solución salina y en infusión i.v. continua, en dosis de $1.25 \mathrm{gr}$. por $\mathrm{kg}$. de peso, utilizada entonces para el tratamiento de la amenaza de parto prematuro, y encontramos que media hora después de suspender la infusión de alcohol, el útero readquiría su actividad contractil, cuando la liberación central de oxitocina aún se encontraba bloqueada por el alcohol circulante remanente, como lo demostraba la falta de respuesta eyectolátea, al realizar una succión con el recién nacido de otra madre, en el seno contralateral (Figura 10).

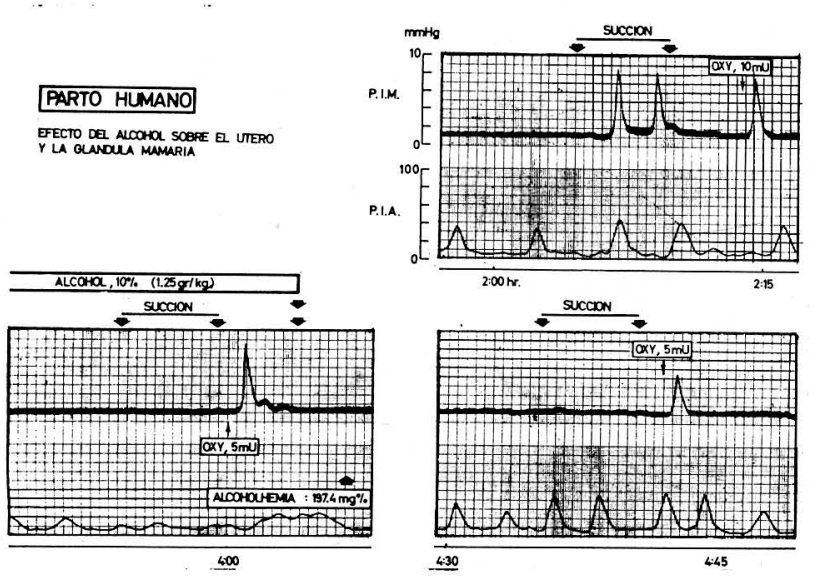

Efecto de la administración de alcohol durante el parto avanzado. Se trata de una mujer en trabajo de parto, con dilatación cervical de $6 \mathrm{~cm}$. En la parte superior derecha se observa el trazado correspondiente a un registro simultáneo de actividad mamaria (PIM) y de actividad uterina (PIA): obsérvese cómo la actividad uterina es normal, y cómo la succión de un recién nacido produce reflejo eyectolácteo, con una liberación aproximada de $20 \mathrm{mU}$ de oxitocina. En el trazado de la parte inferior izquierda, se observa cómo la administración de alcohol produce una marcada disminución de la actividad uterina y la abolición del reflejo eyectolácteo, lo cual estaría indicando que hay una inhibición de la libe- ración neurohipofisiaria de oxitocina y al mismo tiempo una disminución de la actividad uterina. En la parte inferior derecha del gráfico, se observa cómo al suspender la infusión de alcohol, el útero readquiere rápidamente su actividad, cuando al mismo tiempo la succión de un recién nacido demuestra que todavía la neurohipófisis continúa inhibida, ya que no libera oxitocina. Este resultado sugiere entonces la existencia de factores extrahipofisiarios que estarían produciendo la actividad uterina que se observa en el último trazado, cuando la neurohipófisis continua inhibida.

El nombre de la oxitocina viene de raíces griegas que significan: que hace contraer el útero. Sin embargo, y a pesar de que indudablemente "hace contraer el útero", su ausencia demostrada en un fenómeno fisiológico tan transcendente como el parto y en contraste, su presencia indispensable en el mecanismo responsable de la contracción de las células mioepiteliales de la glándula mamaria, o sea en el mecanismo que hace posible la eyección de la leche hacia las vías digestivas del lactante, nos llevó a proponer desde entonces, el cambio del nombre de esta hormona, por el de hormona eyectoláctea, que resulta más adecuado, por exacto, para denominar a la actual oxitocina.

\section{La Inhibición Diferencial de las Hormonas Neurohipofisiarias}

Habiendo demostrado, como vimos otras, que la neurohipófisis humana responde diferencialmente liberando oxitocina o $\mathrm{ADH}$. dependiendo del estímulo que reciba, era lógico estudiar si, de la misma manera, respondía diferencialmente al recibir señales inhibidoras. Utilizamos entonces como inhibidores: la sobrecarga de agua y la administración de soluciones diluídas de alcohol etílico, ambas en infusión endovenosa continua y en 73 voluntarias lactantes.

Para eliminar la posibilidad de que la señal inhibidora no actuara sobre el nivel periférico, o sea sobre el mioepitelio mamario, administramos oxitocina sintética en dosis únicas i.v. de $1,2,5,10$ y $20 \mathrm{mU}$ en un grupo control y en dos grupos experimentales. Como se observa en las figuras 11 y 12 , entre los 3 grupos no existen diferencias significativas, ni en la magnitud, ni en la latencia de los efectos eyectolácteos inducidos por la oxitocina sintética. 
FIGURA 11

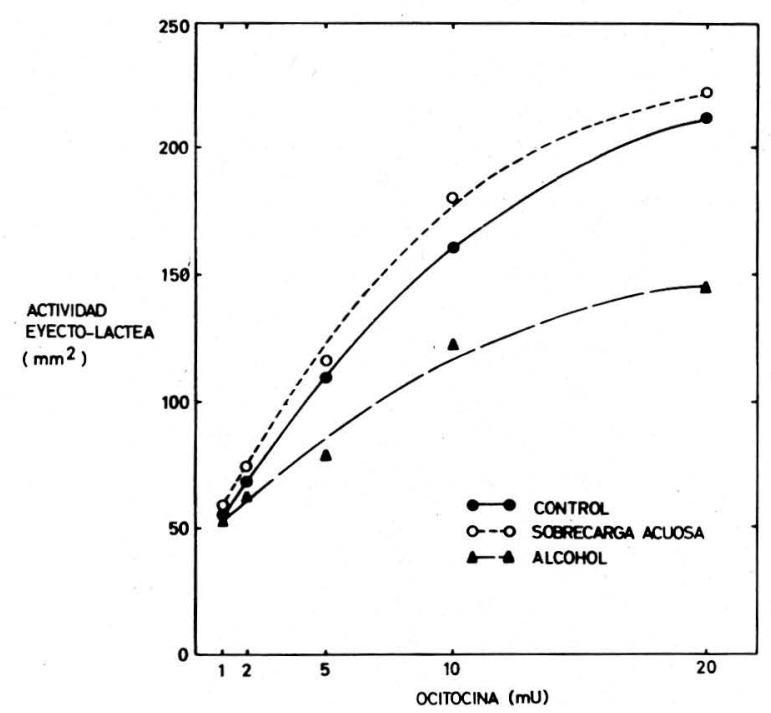

Curva efecto-dosis en los 3 grupos estudiados. Las diferencias no fueron estadísticamente significativas.

FIGURA 12

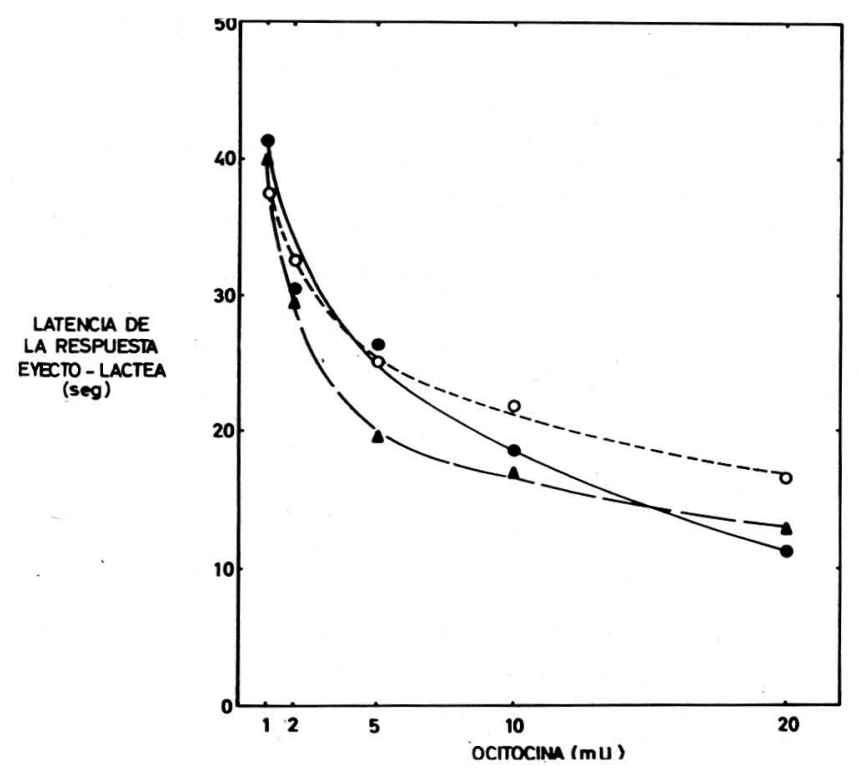

Relación de latencia del efecto con la dosis, en los mismos 3 grupos de la figura anterior. La latencia es menor cuanto mayor es la dosis y las curvas son iguales para los 3 grupos.
La administración de sobrecargas de agua (20 $\mathrm{ml} . / \mathrm{kg}$. peso corporal materno) indujo, como había sido descrito desde la década de 1930-40, una clara inhibición de la actividad antidiurética, produciendo en consecuencia una diuresis acuosa, demostrada por un incremento significativo en la depuración de agua libre (Figura 13, A, B) pero no indujo ningún cambio en la actividad eyectoláctea inducida por la succión del lactante (Figura 14, A, B), ni en la actividad eyectoláctea espontánea, en aquellos casos en los cuales esta actividad aparecía esporádicamente antes y después de la sobrecarga (Figura 15, A, B). Quedaba entonces demostrado que frente a una señal inhibidora como la que utilizamos en esta ocasion, la respuesta neurohipofisiaria era también diferencial al bloquear la liberación de $\mathrm{ADH}$, pero no la de hormona eyectoláctea u oxitocina.

FIGURA 13

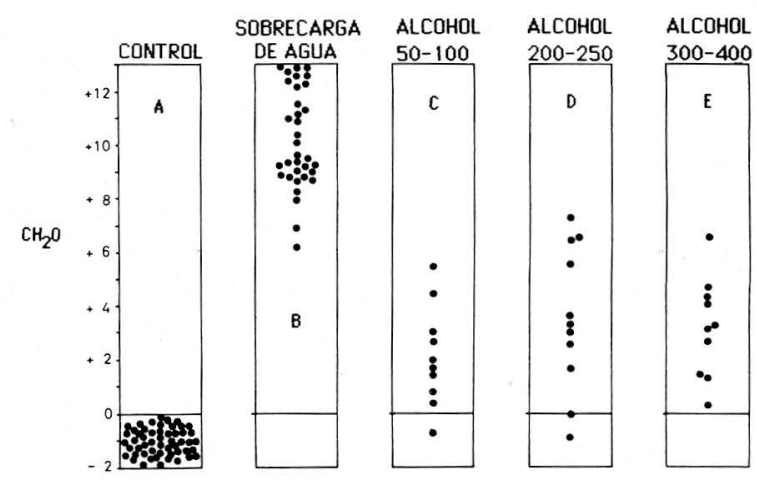

Valores absolutos de la depuración de agua libre en el grupo control (A), y en 4 grupos estudiados. La explicación de los grupos denominados B, C, D y E está en el texto.

La administración de alcohol etílico en dosis que fluctuaron entre 0.15 y $1.92 \mathrm{gr} / \mathrm{kg}$ de peso corporal y que produjeron concentraciones sanguineas entre 50 y $400 \mathrm{mg} / \mathrm{dl}$, mostraron una clara inhibición de la liberación de $\mathrm{ADH}$, sin relación con la concentración sanguinea de alcohol alcanzada (Figura 13, C, D, E). En cambio, la inhibición producida en la liberación de oxitocina, inducida por la succión del lactante, fue mínima, o no se observó ningún cambio, o aumentó en algunos casos (Fi- 
FIGURA 14

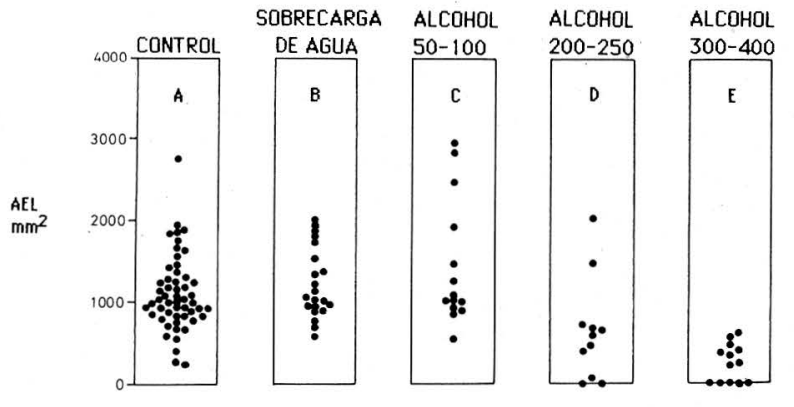

Valores absolutos de actividad eyectoláctea (AEL). Igual forma de representación y de referencia a la de la figura anterior.

gura 16), cuando las dosis de alcohol fueron bajas. Con dosis altas de alcohol el bloqueo del sistema fue muy marcado y en algunos casos fue total (Fi-

FIGURA 15

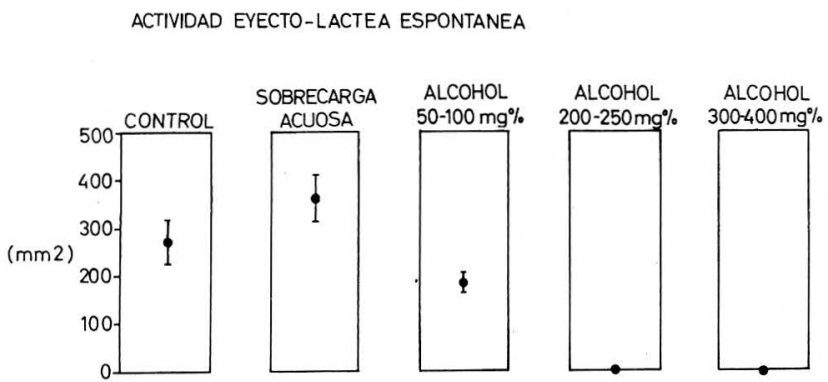

Valores promedio y ESM obtenidos en aquellas lactantes que mostraron actividad eyectoláctea espontánea. Obsérvese la inhibición diferencial, ya que la sobrecarga de agua no la produce, cuando el alcohol sí lo hace de manera completa, cuando las concentraciones sanguíneas de etanol fueron altas.

gura 17). La curva efecto-dosis, que sería plana para la sobrecarga de agua, fue ascendente con dosis bajas, para decrecer exponencialmente en la medida en que se aumentó la dosis (Figura 18).

Estos resultados nos permitieron plantear entonces que la inhibición del sistema central era también diferencial para las hormonas neurohipofisia-

\section{FIGURA 16}

(A) CONTROL

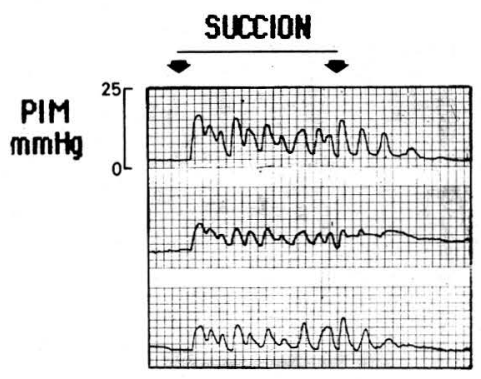

(B) ALCOHOL $0.53 \mathrm{gr} / \mathrm{kg}$

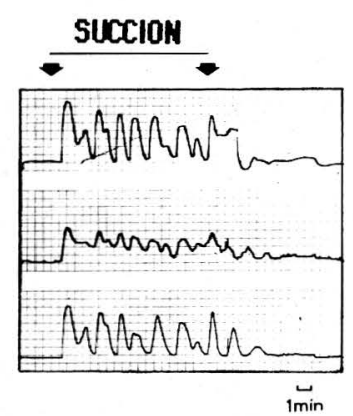

Falta de inhibición de la respuesta eyectoláctea con dosis bajas de alcohol, etílico, registradas en 3 galactóforos de un mismo seno. A: control, B: alcohol $0.53 \mathrm{gr} / \mathrm{kg}$. Obsérvese que durante la infusión de esta dosis baja, la respuesta eyectoláctea es mayor en todos los galactóforos, que en sus controles.

rias, cuando la señal inhibidora es la sobrecarga hídrica, o cuando es una baja concentración de alcohol etílico. Las concentraciones altas de alcohol produjeron una marcada inhibición de ambas actividades, lo cual sugiere una depresión inespecífica de éstas y posiblemente de otras vías neurales, no sólo en el nivel hipotálamo-hipofisiario, sino en niveles más altos, como las vías corticales.

\section{FIGURA 17}
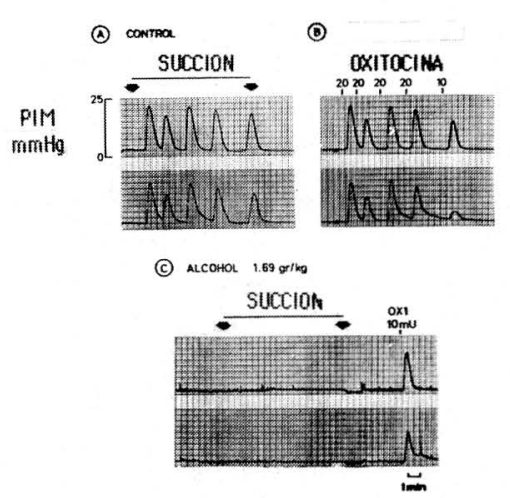

Inhibición completa de la eyección láctea durante una infusión de etanol en dosis altas de $1.69 \mathrm{gr} . / \mathrm{kg}$. (C). Obsérvese en (B) que la cantidad de oxitocina liberada por la succión (A) fue alrededor de $90 \mathrm{mU}$.

Estos resultados continuaban reforzando entonces nuestros hallazgos iniciales que sugirieron 
aferencias neurales diferentes para la liberación neurohipofisiaria de oxitocina y $\mathrm{ADH}$.

\section{FIGURA 18}

\section{ACTIYIDAD EYECTOLACTEA $\Delta \%$}

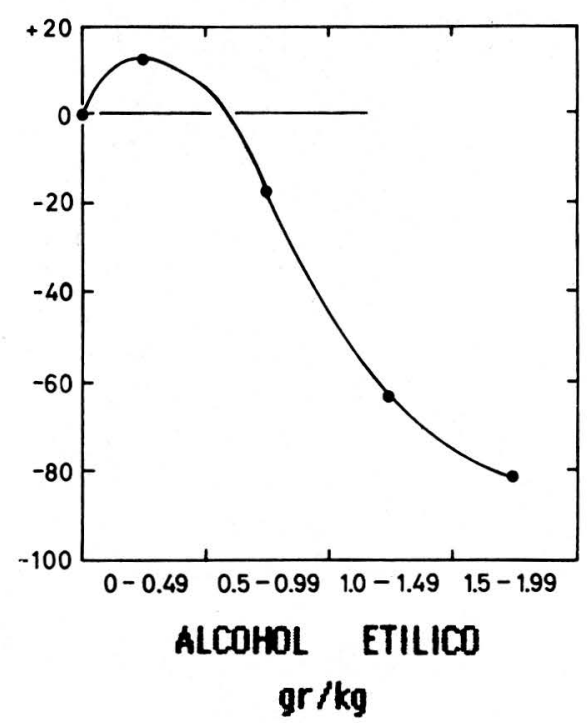

Variaciones porcentuales de la actividad eyectoláctea inducida por la succión, con diferentes dosis de alcohol etílico. Obsérvese que con pequeñas dosis hay un aumento un poco mayor del $10 \%$ y con dosis mayores cae hasta valores de menos $80 \%$

\section{La Acción de las Prostaglandinas}

Las prostaglandinas E y $\mathrm{F}$ habían demostrado activar la función miometrial, así como la de otras estructuras musculares lisas, desde los últimos años de la década de 1960. En los 70, nadie había explorado su acción sobre el mioepitelio mamario humano, que dicho sea de paso, es una estructura bastante olvidada a pesar de su trascendencia en la reproducción humana. Decidimos estudiar su acción y solicitamos unas muestras al Dr. Thomas J. Vecchio, de los Laboratorios Upjohn en Kalamazoo, Michigan, quien generosamente nos envió material para uso en humanos, acompañado de la delicada sugerencia de cambiar nuestro protocolo para no utilizar las dosis únicas propuestas en él, dada la muy corta vida media de estos compuestos, sino la administración de infusiones continuas, similares a las que ya usaban algunos centros de su país, para la inducción del aborto. Como de eso no se trataba y, como además lo uno no descartaba lo otro, decidimos aplicar nuestro protocolo original aceptando que si no funcionaba, nos pasaríamos a las infusiones continuas.

Aplicamos dosis únicas, i.v. de prostaglandinas $\mathrm{F}_{2}$ alfa (PGF 2a), que fluctuaron entre 40 y $200 \mathrm{mi}$ crogramos, en 26 voluntarias lactantes. Encontramos que todas las pacientes respondieron con actividad eyectoláctea, aunque algunas lo hacían sólo con las dosis más altas, otras con las dosis bajas y las altas, y no con las intermedias y más aún, algunas respondían a una dosis dada, y varios minutos después no respondían a esa misma dosis. En algunas, la relación efecto-dosis existía (Figura 19, A) y en otras no ocurrió (Figura 19, B).

FIGURA 19

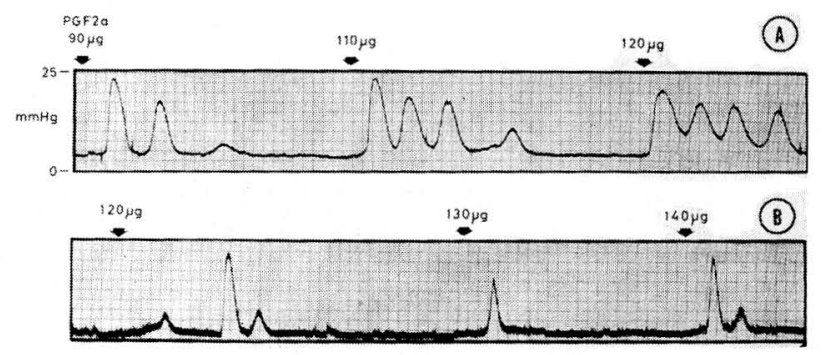

Respuestas eyectolácteas diferentes inducidas por la administración de $P G F_{2 a}$ en dósis únicas y rápidas. H.n el registro superior (A) se observan respuestas mayores, cuanto mayor es la dosis, mostrando así una clara relación efecto-dosis. En cambio, en el trazado inferior (B) esa relación no se observa.

También fue evidente que en la mayoría existía una relación efecto-dosis de tipo lineal, lo cual permitió construir una curva muy aceptable, que incluyó en sus puntos los valores "cero", correspondientes a aquellas lactantes que no respondieron a algunas de las dosis administradas (Figura 20). Lo mismo ocurrió con la latencia de las dosis administradas (Figura 21). Sin embargo, el hallazgo más notable fue el de algunos casos en los cuales las respuestas fueron de duración larga, hasta de 20 minutos, en una de ellas (Figura 22).

Estos resultados nos llevaron a plantear como hipótesis, que el efecto de la PFG2a no ocurría sobre el mioepitelio mamario, sino mediando una descarga central, o neurohipofisiaria, de oxitocina. 
FIGURA 20

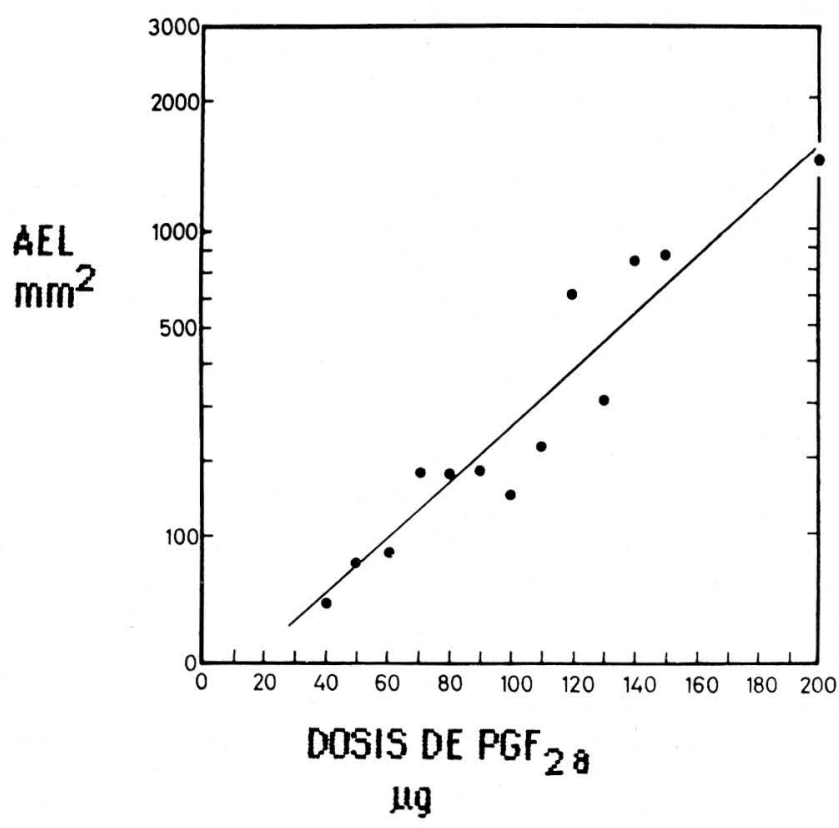

Curva efecto-dosis. La ordenada respuesta la actividad eyectoláctea (AEL) expresada en $\mathrm{mm}^{2}$ y en escala logarítmica. La abscisa representa dosis de $\mathrm{PGF}_{2 \mathrm{a}}$. Se observa una relación lineal.

\section{FIGURA 21}

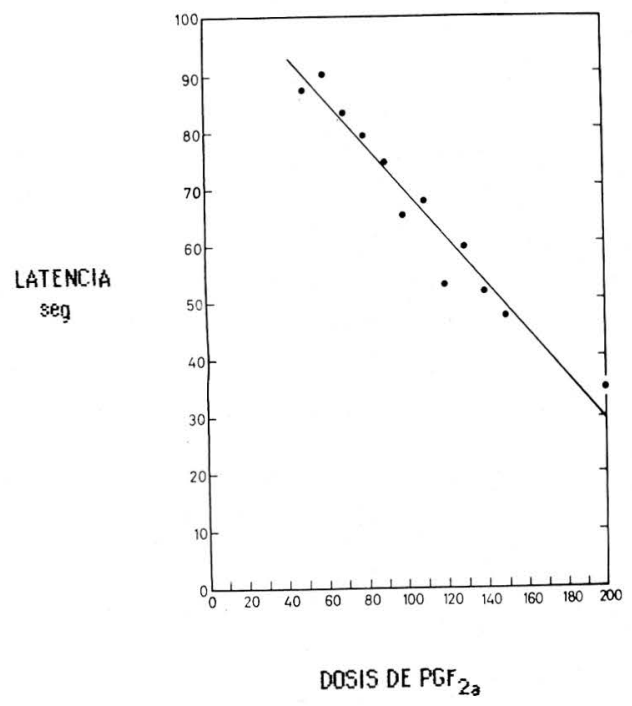

un

Curva efecto-dosis. La ordenada representa la latencia del efecto producido por las diferentes dosis únicas de PGF $_{2 a}$ (abscisa). Obsérvese también una relación lineal que muestra una relación inversa entre la latencia y la dosis.
Realizamos entonces experimentos con glándulas mamarias de rata, cobaya y coneja "in vitro" y encontramos un efecto directo muy pobre, tanto de la PFG2a, como de la PGE1, si se le comparaba con el marcado efecto de la oxitocina que produce respuestas muy rápidas, en contraste con la lenta respuesta de las prostaglandinas (Figura 23).

\section{FIGURA 22}

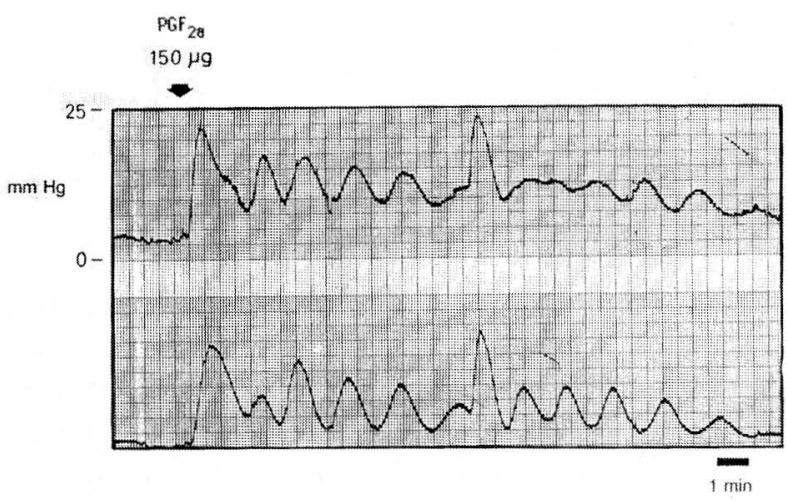

Efecto eyectolácteo muy prolongado de una dosis única de $P G F_{2 \mathrm{a}}$. Se ha registrado en 2 galactóforos de la misma glándula mamaria.

Pero la demostración más aproximada de la hipótesis, la dieron las dosis únicas de PFG2a (la $\mathrm{PGE}_{1}$ produjo efectos colaterales molestos), antes y después de administrar soluciones de alcohol etílico. Estos experimentos demostraron que al blo-

FIGURA 23

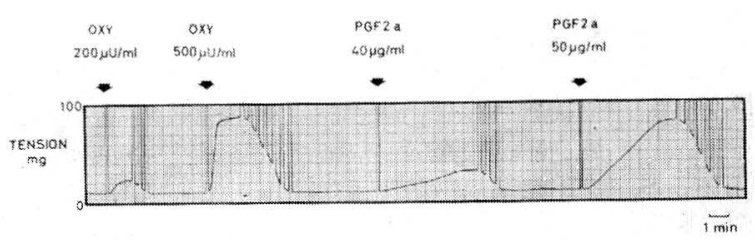

Bioensayo en glándula mamaria de rata “in vitro". Obsérve se cómo la pendiente de la respuesta contractil a la oxitocina (concentraciones en el baño de la tira: 200 y $500 \mathrm{mi}$ crounidades por mililitro) es mucho mayor que la de la $\mathrm{PGF}_{2 \mathrm{a}}(40$ y $50 \mu \mathrm{U} / \mathrm{ml}$.) 
quear el sistema central, no ocurría respuesta eyectoláctea inducida por la PGF 2a, requiriéndose dosis más altas que las utilizadas antes de la infusión de alcohol, para superar el bloqueo y lograr dicha respuesta.

Comunicamos estos resultados a la comunidad científica en 1974, y hasta la fecha siguen reconociéndose en la literatura sobre el tema, pero no conocemos ninguna publicación que haya informado un aporte adicional sobre el papel de esta u otras prostaglandinas en la eyección láctea humana. Queda establecido sí, que estos compuestos hormonales de localización tan ubicua en el organismo humano, juegan un papel cuya trascendencia está aun por establecerse en la eyección láctea en la mujer. El papel de la PFG2a en el mecanismo neurohormonal de lactancia ha sido mucho más estudiado en la rata, destacándose en América Latina el trabajo realizado en el Laboratorio de Reproducción y Lactancia, en Mendoza, Argentina, por Ricardo Deis y sus colaboradores, quienes han demostrado su participación en la inducción de la lactogénesis, utilizando un modelo experimental muy cuidadosamente diseñado.

\section{La Dilatación Vaginal como Estímulo}

Adicional de la Eyección Láctea

En el curso de un trabajo que estudiaba explorar la posibilidad de un efecto agudo de los dispositivos intrauterinos anticonceptivos, (DIU) sobre la eyección de leche y la actividad muscular del útero, diseñamos un grupo control de lactantes en quienes sólo insertábamos un espéculo que se mantenía en la vagina durante 3 minutos. En 25 voluntarias que aceptaron ser sometidas a este estudio como fase previa a la inserción del DIU, registramos la actividad eyectoláctea durante 2 horas, dejando la primera hora para calcular los valores basales; al término de esa primera hora insertamos el espéculo y luego medimos los valores observados en la primera hora. Obviamente, al terminar las 2 horas de estudio insertamos el DIU (asa de Lippes), pero no continuamos con el estudio de sus efectos, para no sesgar los resultados del otro grupo diseñado para inserción de un DIU. En algunos casos insertamos además un fino cateter de polivinilo en la cavidad uterina con el objeto de registrar posibles variaciones de la función miometrial. Este estudio se realizó entre los días 22 y 59 de lactancia.
Como primer hallazgo digno de destacar anotamos una presencia frecuente de actividad eyectoláctea espontánea, la cual ocurrió en cerca del $80 \%$ de los casos y además, aparecía en salvas o grupos de 6 a 10 contracciones continuas, que se repetían 2 a 3 veces por hora, (Figura 24), en contraste con lo observado durante los primeros días de la lactancia, cuando la actividad eyectoláctea espontánea es baja $(20 \%)$ y además, aparece como contracciones únicas

FIGURA 24

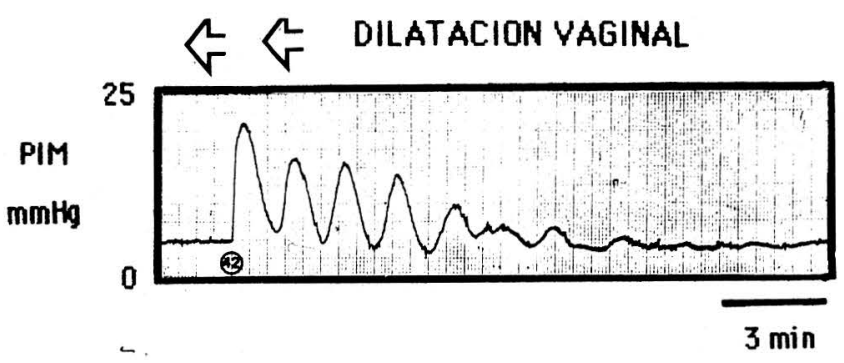

Registro de la presión intramamaria después de la dilatación vaginal en una madre lactante. Obsérvese cómo la aparición de actividad eyectoláctea ocurre 42 minutos después de haber realizado una especuloscopia (ver círculo dentro del trazado). Las contracciones son más coordinadas que las inducidas por la succión, sugiriendo un patrón de liberación hormonal diferente.

o dobles, muy diferentes a las descritas atrás. Además, generalmente las salvas de contracciones fueron coordinadas, es decir que completaron sus fases de contracción y relajación antes de la aparición de la contracción siguiente. Otra diferencia es la intensidad decreciente de estas contracciones (Figura 24). Estas dos características las diferencian de la eyección láctea ya descrita como respuesta a la succión que es incoordinada y muestra contracciones de intensidad variable. No hemos reproducido este patrón de liberación de hormona eyecto láctea, con oxitocina exogena, pero su forma sugiere una descarga única y tal vez en cantidades elevadas de dicha hormona.

La actividad eyectoláctea previa al procedimiento de distensión vaginal tuvo un valor promedio de $426 \pm 76.9 \mathrm{~mm}^{2} /$ hora y de $809.2 \pm 112.8$ después del mismo (Cuadro No. 1). Esta diferencia (Prueba de " $t$ " de Student) es estadísticamente significativa $(\mathrm{P}<0.01)$, demostrando que la distensión 


\section{CUADRO 1}

\section{VALORES PROMEDIO DE ACTIVIDAD EYECTOLACTEA EN 25 MUJERES ENTRE LOS DIAS 22 Y 59 DE LACTAN CIA, ANTES Y DESPUES DE DILATACION VAGINAL POR ESPECULOSCOPIA}

\begin{tabular}{|l|c|c|c|}
\hline $\begin{array}{c}\text { Fase del } \\
\text { Estudio }\end{array}$ & $\begin{array}{c}\text { Actividad } \\
\text { Eyecto-láctea }\end{array}$ & $\Delta$ & P \\
\hline $\begin{array}{l}1 \text { hora } \\
\text { antes }\end{array}$ & $425.9 \pm 76.9$ & - & \\
\hline $\begin{array}{l}1 \text { hora } \\
\text { después }\end{array}$ & $809.2 \pm 112.8$ & $+383.3 \pm 118.4$ & $<0.01$ \\
\hline
\end{tabular}

de la vagina aumenta la eyección láctea espontánea en las mujeres lactantes.

Un hecho importante es que la latencia del efecto eyectolácteo, es decir el lapso transcurrido entre la dilatación vaginal y la aparición del grupo de contracciones mamarias es largo: $20.9 \pm 2.2 \mathrm{mi}$ nutos, en marcado contraste con la latencia de la succión que es de $35.2 \pm 2.5$ segundos (Cuadro No. 2).

\section{CUADRO 2}

\section{VALORES PROMEDIO DE ACTIVIDAD EYECTOLACTEA OBTENIDOS MEDIANTE LA APLICACION DE 2 ESTIMULOS DIFERENTES.}

\begin{tabular}{|c|c|c|c|}
\hline Estímulo & $\mathrm{n}$ & $\begin{array}{c}\text { Latencia } \\
\mathbf{x}(\text { seg.) }\end{array}$ & $\mathrm{P}$ \\
\hline $\begin{array}{c}\text { Succión del } \\
\text { lactante }\end{array}$ & 53 & $35.2 \pm 2.5$ & \\
\hline $\begin{array}{c}\text { Dilatación } \\
\text { experimental } \\
\text { de la vagina }\end{array}$ & 25 & $1.254 .0 \pm 116.3 *$ & \\
\hline
\end{tabular}

* La latencia de la actividad eyectoláctea inducida por la dilatación vaginal que es del orden de los minutos, ha sido expresada en el orden de los segundos para hacer más clara su comparación con la de la succión, que ocurre en este último orden de magnitud.

Estos resultados sugieren una aferencia diferente a la activada por la succión del pezón, cuando el estímulo que lleva la señal de liberación de hormona eyectoláctea, es la dilatación de la vagina. Plantean además, la notable posibilidad de que exis- tiera un mecanismo mediante el cual, esta señal fuera almacenada en una memoria durante varios minutos, al cabo de los cuales y por razones que aún no conocemos, se lanzaría nuevamente desde el sitio de almacenamiento hasta el sistema hipotálamo-neurohipofisiario, produciendo la liberación hormonal y la eyección láctea. En estos momentos estamos realizando un estudio de factibilidad que posibilite un trabajo binacional, con investigadores latinoamericanos que han obtenido resultados tangencialmente comparables con estos, en la rata lactante. Por obvias razones de confidencia científica, aún no podemos publicar estas actividades, pero si debemos dejar consignado que ofrecen extraordinarias posibilidades de continuar haciendo nuevos hallazgos en el campo de la eyección láctea en la mujer.

La liberación refleja de oxitocina, $u$ hormona eyectoláctea, que ocurre durante la succión del seno materno por el lactante, parte del estímulo táctil realizado con la lengua y la boca del niño sobre el pezón, y las presiones que la succión induce en el sistema canalicular de la glándula mamaria, también a través del pezón. Este estímulo compuesto activa la aferencia del reflejo, la cual va por la vía neural medular hasta el sistema hipotálamo-neurohipofisiario, activando allí la aferencia humoral constituída por la liberación de oxitocina al torrente circulatorio. La activación de este reflejo queda establecida entonces como una función de la estimulación del pezón. Sin embargo, desde épocas que se remontan a las culturas preincaicas como la Mochica (500 a.d.C) se encuentran testimonios que expresan en esculturas cerámicas, la existencia de eyección láctea durante la estimulación genital producida por la cópula en la mujer lactante.

Después de esta evidencia, solo conocemos dos publicaciones anecdóticas que en 1953 destacan de nuevo la presencia de eyección láctea durante el coito y/o el orgasmo en mujeres lactantes. La liberación refleja de hormona eyecto-láctea con una aferencia diferente, que partiera de la estimulación vaginal, fue planteada inicialmente a principios de este siglo. En una revisión de la literatura realizada por Reginald Fitzpatrick, de Londres, se menciona a Nuesch. quien afirmó en 1904 que según publicaciones que se remontaban a 1727, los Hotentotes acostumbraban a insuflar aire en la vagina del ganado vacuno para obtener eyección de leche en ausencia de las crías. También informó que los Skyths de 
la India, ordeñaban a las yeguas de esa manera y que en las vacas se obtenía expulsión de leche después de practicar lavados de la vagina o del útero, después de la remoción de restos placentarios en el post-parto, o mediante la insuflación de aire en la vagina.

En 1936, se informó que en las yeguas lactantes, era frecuente observar eyección láctea durante el coito. Más recientemente, se ha descrito que en la vaca, la estimulación manual del cervix produce eyección láctea. En la oveja, se han realizado experimentos muy elegantes y convincentes utilizando la técnica de circulación cruzada, y se observó como la distensión vaginal en una oveja, induce actividad eyectoláctea en la otra, concluyéndose de manera inequívoca que la distensión vaginal produce liberación refleja de una sustancia caracterizada como oxitocina.

\section{El Efecto Inmediato de los Dispositivos Anticonceptivos Intrauterinos}

La información disponible acerca de los efectos que pueda tener la inserción de un dispositivo anticonceptivo intrauterino (DIU) sobre la lactancia humana, es muy escasa. Carlos Gómez-Rogers y su grupo, describieron en 1967 una duración significativamente mayor de lactancia en madres portadoras de un DIU, que en aquellas que no usaron este método. Utilizando como grupo control el que acabamos de describir en el capítulo anterior, medimos la actividad eyectoláctea en otras 25 voluntarias lactantes, estudiando exactamente como en dicho grupo control, la magnitud de la actividad eyectoláctea y su latencia respecto al momento de realizar el estímulo. También, como se ha hecho generalmente se calculó el promedio y el error estandar de la media para dichas variables y se utilizó también la prueba de " $t$ " de Student para muestras pareadas, aceptando un nivel de significancia de $\mathrm{P} \ll 0.05$.

Se encontró actividad eyectoláctea espontánea solo en el 48 de los casos (12/25), la cual es menor que en el grupo control, pero, mayor que en los primeros días de la lactancia, como ya lo describimos antes. Sólo en estos casos pudo realizarse el estudio, ya que en los 13 restantes no hubo actividad eyectoláctea ni antes, ni después de la inserción del DIU.

La actividad eyectoláctea encontrada después de la inserción de DIU, fue del mismo tipo de la que ocurrió después de la distensión vaginal (Figura 25), con un valor promedio menor, pero no significativo estadísticamente (Cuadro 3).

FIGURA 25
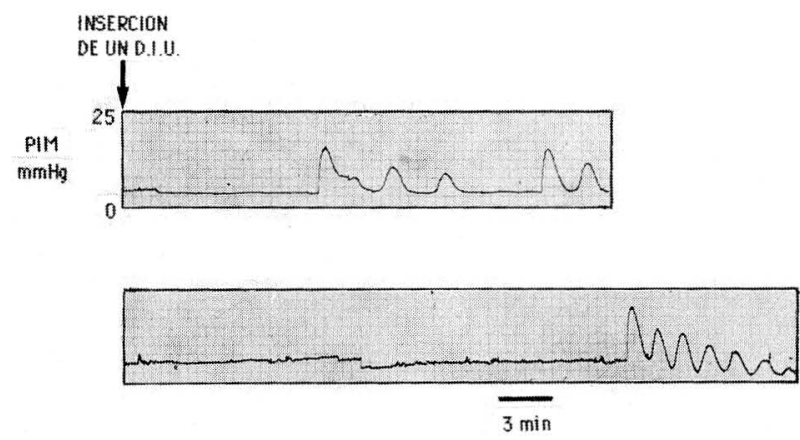

Registro de la presión intramamaria después de la inserción de un dispositivo anticonceptivo intrauterino en 2 lactantes normales. La actividad es comparable a la inducida por la dilatación vaginal expuesta en la figura anterior. Las latencias son más cortas en ambos casos: $10.5 \mathrm{~min}$. (trazado superior) y $27.5 \mathrm{~min}$. (trazado inferior).

La latencia de la primera y la segunda salva de respuestas eyectolácteas, fue también menor, pero tampoco resultó estadísticamente significativa (Cuadro 4). Curiosamente, y esto da cierta mayor validez

$$
\text { CUADRO } 3
$$
VALORES PROMEDIO DE LA ACTIVIDAD EYECTO-
LACTEA INDUCIDA EN LOS 2 GRUPOS ESTUDIADOS

\begin{tabular}{|l|c|c|c|}
\hline $\begin{array}{l}\text { Grupo } \\
\text { Estudiado }\end{array}$ & $\mathbf{n}$ & $\begin{array}{c}\text { Actividad } \\
\text { Evectolátea } \\
\text { (mm/hora) }\end{array}$ & $\mathbf{P}$ \\
\hline Control & 25 & $809.2 \pm 112.8$ & \\
\hline DIU & 25 & $739.7 \pm 164.6$ & N.S. \\
\hline
\end{tabular}

al argumento que hubiera podido invalidar los resultados obtenidos en aquellos casos en los cuales insertamos un cateter in trauterino (Figura 26) además del cateter mamario, la latencia de la respuesta eyectoláctea fue más larga en los casos en quienes se estudió la función miometrial y ésta si resultó estadísticamente significativa (Cuadro 4).

Estos resultados demuestran que la estimulación genital producida mediante dilatación vaginal 


\section{CUADRO 4}

\section{VALORES PROMEDIOS DE LA LATENCIA DE LA ACTIVIDAD EYECTOLACTEA. SEGUN EL METODO UTILIZADO}

\begin{tabular}{|l|c|c|}
\hline Procedimiento & $\begin{array}{l}\text { Latencia del ler. } \\
\text { Episodio (minutos) }\end{array}$ & $\begin{array}{c}\text { Latencia del 2o. } \\
\text { Episodio (minutos) }\end{array}$ \\
\hline $\begin{array}{l}\text { A: Distension } \\
\text { vaginal }\end{array}$ & $20.9 \pm 2.2$ & $34.4 \pm 3.9$ \\
\hline $\begin{array}{l}\text { A } \pm \text { B: Inserción } \\
\text { de un cateter } \\
\text { intrauterino }\end{array}$ & $30.8 \pm 2.8 *$ & $42.8 \pm 2.5 * *$ \\
\hline $\begin{array}{l}\text { A } \pm \text { B } \pm \text { C: } \\
\text { Inserción de un } \\
\text { DIU }\end{array}$ & $15.4 \pm 2.2^{*}$ & $26.2 \pm 3.6 * *$ \\
\hline
\end{tabular}

induce liberación de hormona oxitócica, o eyectoláctea, y que esta liberación se facilita, a juzgar por el acortamiento de la lactancia, cuando se inserta un DIU. Este hecho sugiere que ese podría ser, sólo en el momento de su inserción, uno de los activadores del sitio de almacenamiento de tal información, o en otras palabras, de la memoria guardada después de la dilatación vaginal.

\section{FIGURA 26}

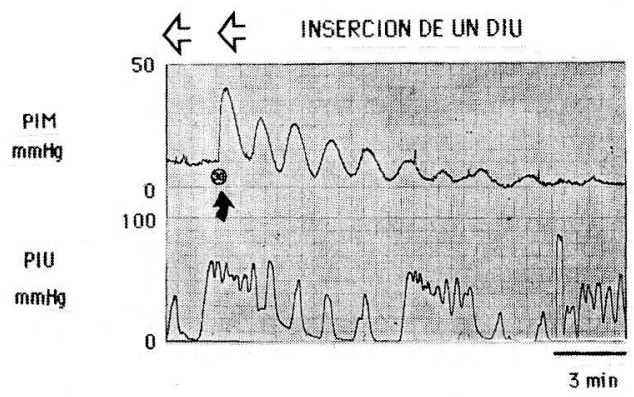

Registro de las presiones in tramamaria (PIM) e intrauterina $(P I U)$ en una mujer lactante. La actividad eyectoláctes ocurre 30 minutos después de la inserción del DIU. Obsérvese que la actividad del útero no es alta. En varios casos no observamos aumentos significativos de la actividad miometrial después de la inserción del DIU.

Podrían existir otros mecanismos activadores de la posible memoria cerebral, que serán objeto del diseño experimental que hemos mencionado atrás, como nuestra actividad de los próximos años y que en esta oportunidad no está orientada hacia el goce del "discreto encanto" de la investigación pura, sino por el contrario, hacia la búsqueda de la aplicación inmediata del aporte original al manejo de la lactancia humana, fascinante actividad que como se acaba de describir, ha ocupado un espacio vital de casi tres décadas en nuestro diario trabajo universitario.

\section{AUTORES RECOMENDADOS Y BIBLIOGRAFIA PERSONAL}

Si aceptamos que el arte es, como la ciencia, una expresión humanista que sólo puede entenderse como una búsqueda incesante de la verdad, esta línea de trabajo bien pudo haberse universalizado por primera vez cuando Jacopo Robusti (1518-1594), conocido como Tintoretto por el oficio de su padre y por su “pequeña estatura”, pintó un hermoso lienzo que hoy cuelga en la Galería Nacional de Londres y que tituló EL ORIGEN DE LA VIA LACTEA. En él siguiere por primera vez, y bellamente, un mecanismo central de control de la eyección láctea, cuando Hera amamanta a Heraclio, un hijo de Zeus, Dios de Dioses, y al hacerlo con el seno izquierdo, inunda los cielos con su leche que fluye también del seno derecho.

Mitología aparte, digamos que en un artículo que abarca un período de casi 3 décadas de trabajo, resultaría excesivo publicar todas las referencias consultadas por nosotros en ese lapso. Por ello, preferimos recomendar sólo algunos de aquellos autores cuyos trabajos experimentales fueron el resultado de la dedicación de su vida, o de una parte de ella, al estudio y al aporte de conocimiento nuevo en este campo, y que han sido guía para nuestro modesto contingente. Ellos son, en Inglaterra: el grupo que inició Sir Henry Dale y que tuvo cultores como S. Folley, G. Knaggs, J.S. Tindall, F. Ely, W.E. Petersen, H. Van Dyke, J.L. Linzell y L.R. Findlay, entre muchos otros. En Estados Unidos de Norteamérica: M. Newton, N. Newton, C.E. Grosvernor, D. Jelliffe y P. Jelliffe. En Argentina: S. Taleisnick, J.M. Voloschin, N. Sala y Ricardo Deis. En Chile, Cárlos Gómez y sus colaboradores y Horacio Croxatto y Soledad Díaz, entre muchos otros. En México: Flavio Mena y Carlos Beyer y en Uruguay: Y. Sica-Blanco, V. GonzálezPanizza, C. Méndez-Bauer, C. Fielitz, R. Caldeyro-Barcia, J. Coch y L. Branda. En la lectura de sus trabajos clásicos, se encontrarán muchas otras referencias que ayudarán al lector interesado en este campo.

Nosotros hemos publicado artículos originales y también muchos de divulgación científica en revistas, reuniones 
y simposios nacionales e internacionales; se citan casi todos los relacionados en forma directa con la eyección láctea:

1. SALA, N.; SICA-BLANCO, Y.; COBO, E. Algunos Aspectos Farmacológicos de la Eyección Láctea de la Mujer. III Congr. Uruguayo Ginecotocol. 1960: 2; 297.

2. MENDEZ-BAUER, C.; FITZPATRICK, R.J.; CABOT, H.M.; BRANDA, L.; ESCARCENA, L.; FIELITZ, C.; GONZALEZPANIZZA, V.; COCH, J.A.; POSEIRO, J.J.; SICA-BLANCO, Y.; SALA, N.; ALVAREZ, H.; GOMEZ-ROGERS, C.; FERNANDEZ, R.; COBO, E. y CALDEYRO-BARCIA, R. Potencia Eyectoláctea del Plasma Humano durante el Embarazo, Parto y Puerperio. III Congr. Uruguayo Ginecotocol. 1960: 2; 307.

3. СОво, E у ALVAREZ, H. La eyección láctea en la mujer. Curso sobre contractilidad uterina. Centro de Estudios Leonor Méndes de Barros. Sao Paulo. Brasil. 1960.

4. СОВО, E. Estudio experimental de la función neurohipofisiaria en el estado grávido puerperal humano. $V$ Congr. Asoc. Lat-Am. Cien. Fisiol. Caracas. Venezuela. 1963.

5. СОВО, E. Evidencias de una secreción independiente de las hormonas neurohipofisiarias durante el embarazo y la lactantancia. II Congr. Col. Obstet. Ginecol. Medellín. Colombia. 1963.

6. СОВо, E. Estudio de la interacción periférica de oxitocina y vasopresina en el humano. V Congr. Col. Obstet. Ginecol. Medellín. Colombia. 1963.

7. СОВO, E. Liberación de oxitocina y vasopresina durante el embarazo, el parto y la lactancia humana. IV Congr. Mundial Obstet. Ginecol. Mar del Plata. Argentina. 1964.

8. СОВО, E. Función neurohipofisiaria en el embarazo y la lactancia humanas. I Reunión de ALIRH. Montevideo. Uruguay. 1964.

9. GaitAN, E.; COBO, E. and MIZRACHI, M. Evidence for the differential secretion of oxytocin and vasopressin in man. J. Clin. Invest. 1964: 43; 2310.

10. СОВО, E. Función neurohipofisiaria durante el parto humano. Estudio simultáneo de las actividades oxitocica y antidiurética. II Reunión de ALIRH. Viña del Mar. Chile. 1966.

11. СОВО, E. Activación diferencial de la neurohipófisis humana. XII Congr. Méd. Centroamericano. Tegucigalpa. Honduras, 1967.
12. COBO, E.; de BERNAL, M.; GAITAN, E. and QUINTERO, C.A. Neurohypophyseal hormone release in the human. II Experimental study during lactation. Am. J. Obstet. Gynecol. 1967: 97; 519.

13. COBO, E. Neurohypophyseal function during pregnancy, labor and lactation. Ist. Internatl. Symp. on uterine physiol. \& pharmacol. Cornell University. New York. U.S.A. 1968.

14. COBO, E. Inhibición neurohipofisiaria en la lactancia humana. III Reunión de ALIRH. Bahía. Brasil. 1968.

15. СОВО, E. Uterine and milk-ejecting activities during human labor. J. Appl. Physiol. 1968: 24; 317.

16. COBO, E. de BERNAL, M.; QUINTERO, C.A. and CUADRADO, E. Neurohypophyseal hormone release in the human. III-Experimental study during labor. Am. J. Obstet. Gynecol. 1968: $101 ; 479$.

17. COBO, E. Questioning the role of oxytocin in human labor. Conference by invitation. New York Hospital. Cornell University Medical School New York. USA. April, 1969.

18. COBO, E. and QUINTERO, C.A. Milk-ejecting and antidiuretic activities under neurohypopseal inhibition with alcohol and water overload. Am. J. Obstet. Ginecol. 1969: 105; 877.

19. СОВО, E. Inhibición de la neurohipófisis en la lactancia humana, Rev. Soc. Colomb. Endocrinol. 1969: 7; 5 .

20. СОВо, E. Función neurohipofisiaria en el estado grávido puerperal humano. I Jornadas Ecuat. Endocrinol. Quito. Ecuador 1970.

21. COBO, E. Control Hormonal del Parto. Rev. Col. Obstet. Ginecol. 1970: $21 ; 455$.

22. СОВО, E. Fisiología de la eyección láctea. II Sem. Regional ALIRH. Quito. Ecuador. 1970.

23. СОВO, E. Función neurohipofisiaria en la diabetes insípida. IV Reunión de ALIRH. Ixtapán de la Sal. México. 1970.

24. COBO, E. Fisiología de la lactancia. III Sem. Regional ALIRH. Caracas. Venezuela. 1971.

25. СОВО, E. Experiencias sobre actividad eyectoláctea y uterina al insertar un DIU en madres lactantes. IX Congr. Col. Obstet. Ginecol. Bucaramanga. Colombia. 1971.

26. COBO, E.; de BERNAL, M. and GAITAN, E. Low oxytocin 
secretion in diabetes insipidus associated with normal labor. Am. J. Obstet. Ginecol. 1972: 114; 861.

27. COBO, E. Efecto inmediato de la inserción de un dispositivo intrauterino sobre el reflejo eyectolácteo. V Reunión de ALIRH. Buenos Aires. Argentina. 1972.

28. СОВО, E. Effect of different doses of ethanol on the milkejecting reflex in lactating women. Am. J. Obstet. Gynecol. 1973: $115 ; 817$.

29. COBO, E. Reproducción Humana. El sistema hipotálamohipofisiario. Ed. Fepafem. 1ra. Edición. Bogotá. Colombia. 1973.

30. СОВO, E. Fisiología de lactancia. Seminario OPS sobre Fi siología de la Reproducción Humana. Venezuela. 1973.

31. COBO, E. Prostaglandinas en reproducción. IV Sem. Regional ALIRH. San José. Costa Rica. 1973.

32. COBO, E. Lactancia y cuidado post-parto. V Cursillo de Fisiología de la Reproducción y Atención Integral de la Madre. Universidad Peruana Cayetano Heredia. Lima. Perú. 1973.

33. СОВО, E. Papel de las prostaglandinas en la reproducción. VII Congr. Lat-Amer. Obstet. Ginecol. Quito. Ecuador. 1973.

34. COBO, E. Efecto de las prostaglandinas sobre el reflejo eyectolácteo. VIII Congr. Col. Cien. Biol. Cali. Colombia. 1973.

35. СОВО, E. Aspectos endocrinológicos y epidemiológicos de la lactancia humana. X Congr. Col. Obstet. Ginecol. Cali. Colombia. 1973 .

36. COBO, E. Epidemiología de la lactancia y su relación con el uso de agentes anticonceptivos. VI Reunión de ALIRH. Simposio sobre lactancia. Lima. Perú. 1974.

37. COBO, E. y VILLAMIZAR, M. Efecto eyectolácteo de la prostaglandina $F_{2 a}$. VI Reunión de ALIRH. Lima. Perú. 1974.

38. COBO, E.; RODRIGUEZ, A. and VILlAMIZAR, M. Milkejecting activity induced by prostaglandin F2a. Am. J. Obstet. Gynecol. 1974: 118; 831.

39. СОВO, E. Regulación de la lactancia humana. XII Sem. Centro-Am. Sobre Avances Recientes en Biología de la Reproducción. Guatemala, 1974.

40. COBO, E. Neuroendocrine control of the milk-ejecting reflex in women. In: Lactogenic Hormones, Fetal Nutrition and
Lactation. John Willey \& Sons Inc. Ed: Josimovich, J ; Reynolds, M. and СОВO, E. 1ts. Edition. 1974.

41. COBO, E. Mecanismos reguladores de la eyección láctea en la mujer. V Jornadas Panam. Obstet. Ginecol. Panmá. 1975.

42. COBO, E. Epidemiología de la lactancia. VIII Congr. Lat-Am. Obstet. Ginecol. La Habana. Cuba. 1976.

43. СОВО, E. Aspectos médico-sociales de la lactancia humana. VIII Congr. Mundial Obstet. Ginecol. México. 1976.

44. COBO, E. Fisiología del eje hipotálamo-hipófisis-ovarios. XV Reunión Soc. Col. Endocrinol. Manizales. Colombia. 1978.

45. СОВO, E. Regulación endocrina del parto. En: Reproducción. Eds. E. Cobo; G. López-Escobar y G. Pérez-Palacios. CCRP. Bogotá. 1ra. Edición, Págs. 559 - 585. 1979.

46. СОВO, E. Prostaglandinas en reproducción. Lactancia humana I. Eyección láctea. I Curso Latinoamericano de Reproducción. UNESCO. LARLAC. Mendoza. Argentina. 1979.

47. COBO, E. Efecto de la instrumentación genital sobre las actividades eyectoláctea y u terina en madres lactantes. XIII Congr. Col. Obstet. Ginecol. Bogotá. Colombia. 1979.

48. COBO, E. Regulación neuroendocrina de la eyección láctea. Asoc. Col. Cien. Biol. Medellín. Colombia. 1980.

49. COBO, E. Efecto de la instrumentación genital y de la inserción de un dispositivo intrauterino (DIU) sobre las actividades eyecto-láctea y uterina en madres lactantes. Rev. Soc. Col. Endocrinol. 1980: 12; 71.

50. COBO, E. Lactancia natural. VII Reunión de ALIRH. Mendoza. Argentina. 1981.

51. COBO, E. Situación actual de la lactancia materna en el mundo. Simp. Col. Educ. Psicofis. Bogotá. Colombia. 1981.

52. СОВO, E. The importance of breast feeding for the mother and child. Xth. World Congr. Obstet. Gynecol. San Francisco. USA. 1982.

53. COBO, E. Endocrinología de la lactancia. III Simp. Nal. Endocrinol. Repro. Bogotá. Colombia. 1982.

54. СОВО, E. The phy siology of milk-ejection in lactating women. In: Full Proceedings Xth World Congr. Obstet. Ginecol. Ed. M. Newton. Acad. Prof. Inf. Serv. Inc. New York. Pags. 131-139. 1983. 
55. COBO, E. Lactancia Materna. Curso de Actualización. Soc. Pediatría Bolivar. Cartagena. Colombia. 1983.

56. СОВO, E. Endocrinología de la lactancia. 1er. Simp. MatInfantil del Caribe. Cartagena. Colombia. 1984.

57. СОВO, E. Lactancia y Fecundidad. Epidemiología. X Reunión de ALIRH. Viña del Mar. Chile. 1986.
58. СОВО, E. Fisiología de la lactancia y su relación con la infertilidad natural post-parto. XII Congr. Lat-Am. Obstet. Ginecol. Guatemala. 1987.

59. СОВO, E. Lactancia e infertilidad. XVII Congr. Col. Obstet. Ginecol. Pereira. Colombia. 1987.

60. COBO, E. Aporte latinoamericano al conocimiento científico de la lactancia. XI Reunión de ALIRH. Puerto Vallarta. México. 1988.

\title{
40 AÑOS DE LA REVISTA COLOMBIANA DE OBSTETRICIA Y GINECOLOGIA
}

\author{
CURSO DE ACTUALIZACION
}

Para conmemorar los 40 años de vida de la Revista, se realizará un Curso de Actualización en Ginecologia y Obstetricia, los días 16 y 17 de marzo de 1989.

Próximamente se suministrará amplia información sobre el programa científico con la participación de profesores nacionales e invitados extranjeros y de costos de suscripción.

La Dirección 